\title{
Planejamento de uma atividade de Educação Interprofissional para as profissões da saúde
}

Ana Paula Griggio, Vivian Aline Mininel, Heloise Lima Fernandes Agreli, Jaqueline Alcântara Marcelino da Silva

\section{Resumo}

Introdução: Investir na formação dos profissionais por meio da educação interprofissional e da prática colaborativa qualifica-os para a assistência integral às necessidades de saúde dos indivíduos, considerando o trabalho como um determinante de saúde. Objetivo: Descrever a etapa de planejamento de uma atividade intitulada "Educação Interprofissional para atenção à saúde do trabalhador na Atenção Primária à Saúde". Método: Alicerçado na Pesquisa- Ação, o planejamento foi desenvolvido em uma instituição federal de ensino superior do Estado de São Paulo em formato de oficinas, que contaram com a participação de um moderador, um observador, seis docentes (duas fisioterapeutas, uma educadora física e três enfermeiras), uma estudante de graduação e uma estudante de pós-graduação. Os dados foram coletados em um diário de campo. Resultados: As oficinas possibilitaram a definição de: (1) Competências profissionais comuns: Compreender o modelo de atenção à saúde, embasado na integralidade e nas necessidades em saúde individuais e coletivas; Compreender o trabalho como determinante social do processo saúde-doença; Identificar atitudes que provoquem mudanças na prática profissional, compreendendo a influência do trabalho no adoecimento; (2) Objetivos de aprendizagem: Sensibilizar sobre o papel dos diferentes profissionais na APS com ênfase na saúde do trabalhador, Compreender a determinação social do processo saúde-doença; Desenvolver habilidades para o trabalho em equipe; Reconhecer o perfil epidemiológico e produtivo; Compreender a estrutura da RAS; Compreender as ações e avanços no campo da saúde do trabalhador na APS; (3) Estratégias pedagógicas: Metodologias ativas de aprendizagem, considerando a centralidade do aluno em seu desenvolvimento; (4) Estratégia de avaliação: Desenvolvimento de um estudo de caso sobre o cuidado interprofissional de um trabalhador na RAS. Conclusão: O planejamento resultou em uma atividade consistente, concebida por múltiplas experiências, conhecimentos e perspectivas, potencializando a integralidade do cuidado.

Descritores: Integralidade em saúde, Relações interprofissionais, Educação Superior, Saúde do trabalhador 